\title{
ESTUDOS SOBRE ALIMENTAÇÃO: ENTRE SABERES DA VIDA COTIDIANA \\ E IMPASSES AGROINDUSTRIAIS
}

\author{
FOOD STUDIES: BETWEEN KNOWLEDGE OF EVERYDAY LIFE AND \\ AGRIBUSINESS IMPASSES

\section{ESTUDIOS ALIMENTARIOS: ENTRE EL CONOCIMIENTO DE LA VIDA COTIDIANA Y LA AGROINDÚSTRIA}

\author{
Henrique Soares Carneiro \\ henricarneiro@uol.com.br
}

\begin{abstract}
RESUMO: Os estudos sobre história da alimentação abrangem a sobrevivência dos povos e dos indivíduos, mas podem ser enfocados analiticamente em um nível micro e em outro macro. No âmbito da culinária enfoca-se uma história do cotidiano e das sensibilidades. Na história da agroindústria e indústria da alimentação verifica-se 0 esgotamento dos recursos naturais e uma irracionalidade sistêmica que compromete as condições de sustentabilidade socioambiental, ou seja, do metabolismo entre a humanidade e a natureza. O artigo enfoca alguns autores que buscaram situar a história desse desequilíbrio ecológico e social ao longo das revoluções agrícolas e industriais, destacandose Michael Pollan e John Bellamy Foster e, no âmbito da história do cotidiano, o estudo de Luce Giard.
\end{abstract}

Palavras-chaves: história da alimentação, revolução industrial, agricultura, ecologia, culinária

SUMARY: Studies on food history include the survival of peoples and individuals, but they can be approached analytically, at a micro or a macro level. A culinary approach focuses on the history of everyday life and human sensitivities. In the history of agribusiness and the food industry, we will look at the depletion of natural resources, in a systemic irrationality that undermines environmental sustainability, that is, the metabolism between humanity and nature. The article focuses on a few authors who sought to situate the history of these ecologic and social imbalances during the agricultural and industrial revolutions, especially Michael Pollan and John Bellamy Foster, and in the history of everyday life, studies by Luce Giard.

Keywords: food history, industrial revolution, agriculture, ecology, culinary 
RESUMEN: Los estudios sobre la historia de los alimentos incluyen la supervivencia de los pueblos y las personas, pero se puede abordar analíticamente a nivel micro y macro. Em la dimensión culinária es una historia de la vida cotidiana y las sensibilidades. En la historia de la agroindustria y la industria alimentaria sucede un agotamiento de los recursos naturales y una irracionalidad sistémica que socava las condiciones para la sostenibilidad del medio ambiente, es decir, el metabolismo entre la humanidad y la naturaleza. El artículo se centra en algunos autores que trataron de situar la historia de este desequilibrio ecológico y social en las revoluciones agrícola e industrial, especialmente Michael Pollan y John Bellamy Foster y dentro de la historia de la vida cotidiana, el estudio de Luce Giard.

Palabras-clave: historia de la alimentación, revolución industrial, agricultura, ecologia, culinária

A alimentação como elemento definidor de um campo de pesquisa é um tema cujas fronteiras são demasiado amplas, sendo comum a afirmação de sua importância, universalidade, condição fundadora das civilizações, eixo organizador dos sistemas de classificações, o mais forte mediador afetivo e formador dos laços e identidades das comunidades.

A alimentação é o fenômeno mais amplo da reprodução das sociedades (não apenas humanas) por meio da incorporação de substâncias externas ao nosso corpo, necessárias para repor sua energia e sua carne. O que comer, como produzir, estocar, transportar e preparar, eis a questão.

Em última instância, como escreveu Michael Pollan, todos comemos um pedacinho do sol, pois dele as plantas tiram a energia para constituir as suas cadeias complexas de carbono. Hoje em dia, comemos também o combustível fóssil que cada vez mais se incorpora ao processo produtivo e distributivo da agroindústria.

Por isso, falar de alimentação é falar de cadeias alimentares, de agroindústria, de mercado de commodities, de "food power", elemento estratégico nas relações internacionais. E é também falar de uma crise civilizatória, um sistema produtivo agroindustrial que a comunidade científica de forma praticamente unânime vem apontando como responsável pelo aumento da emissão de derivados de carbono na atmosfera, além de outros problemas de agropoluição. 
Estudos sobre alimentação: entre saberes da vida cotidiana e impasses agroindustriais, pp. 93-103.

O tema da alimentação é assim, "imperial", abrange e invade praticamente tudo. Por isso, ao falar da história da alimentação é preciso começar por delinear o objeto em questão.

Num esquema geral, poderíamos dividir as instâncias como "macro" e "micro". No primeiro grupo, estaria a alimentação como produção e distribuição dos bens, como história econômica e, especialmente, história da agricultura e, em se tratando da época moderna, das relações agrícolas e industriais.

Esse aspecto é absolutamente central. Define, em grande parte, os contornos da crise civilizacional sócio-ambiental, ora em curso acelerado.

No outro âmbito, do micro, temos a vida cotidiana, a onipresença na organização da vida cotidiana do alimento, da sua busca, preparo, consumo e dos imensos e valiosos significados afetivos neles investidos.

É de uma história do cotidiano que, então, se trata, como a empreitada impulsionada por Michel de Certeau $^{1}$, nos anos 70, publicados na coletânea $A$ Invenção do Cotidiano, em que Luce Giard dá conta do tema "Cozinhar", mostrando como essa prática foi tradicionalmente relegada ao mundo feminino, a uma esfera do "invisível cotidiano", de um trabalho desvalorizado e sem renda, mas que, como as técnicas do corpo, de Mauss, assume a condição de um saber prático, que é uma "ciência prática do singular", uma busca do conhecimento da oralidade, do ordinário, do "anônimo inominável" que se esconde nas cozinhas, mas investe-se de um alto grau de ritualização e investimento afetivo, moldando a memória infantil e ensinando uma sabedoria dos gestos e das palavras que sofrem mutações radicais com a era dos eletrodomésticos no segundo pós-guerra.

Culinária é o saber prático da vida cotidiana, é a cozinha, é a horta, é a despensa familiar, e, finalmente, a copa, os pratos, os hábitos. Domínio relegado à uma esfera considerada por muito tempo inferior, a esfera

\footnotetext{
${ }^{1}$ Michel de Certeau, Luce Giard, e Pierre Mayol, A invenção do cotidiano, 2. Morar, Cozinhar, $8^{a}$ Ed., Editora Vozes, 2008.
} 
feminina, oposto ao domínio da vida pública e da economia formal, essa sabedoria culinária das avós, gestoras dos preparos e dos temperos, muito mais dos que os manuscritos de receitas constitui uma imensa memória afetiva infantil. Culinárias são técnicas de sobrevivência, são formas de adaptação, são gestos e gostos estabelecidos, são identidades familiares, étnicas, regionais.

Na acepção de Luce Giard, a culinária é, portanto, uma forma de saber prático, uma técnica e uma arte da vida cotidiana, fonte agregadora e formadora das representações simbólicas ligadas aos sentimentos de gosto como pressupostos básicos do conhecimento sensível em que o saboroso e o repugnante constituem-se na palheta básica para matizar comparativamente todas as outras esferas da sensibilidade e da sensualidade.

Como todo saber prático, constitui-se também como matriz simbólica fundamental dos ciclos das estações, da vida e da morte, da produção e da destruição. Integra a humanidade e a natureza no metabolismo das consubstanciações das coisas comíveis e nas mitologias das plantas e dos animais.

Como técnica de sobrevivência, podemos falar inclusive de uma culinária da fome.

Já uma gastronomia da fome nunca poderia existir, por definição, pois a gastronomia é uma codificação da distinção social das elites por meio de alimentos e formas de comer emblemáticas. A culinária é o cotidiano e a gastronomia é o luxo. Como linguagem sensorial se constitui em forma de expressão artística e se insere numa cultura mais geral do gosto e serve de veículo identitário nacional e regional.

No sentido macro, entretanto, a historiografia da alimentação é a crônica de nossos impasses, dos "dilemas do onívoro", conforme o título do livro de Michael Pollan². Se podemos comer de tudo, porque comemos o que comemos? O que é a alimentação das massas, as cadeias alimentares, a agroindústria, do milho ao fast-food?

\footnotetext{
${ }^{2}$ Michael Pollan, O Dilema do Onívoro, Rio de Janeiro, Intrínseca, 2007.
} 
Estudos sobre alimentação: entre saberes da vida cotidiana e impasses agroindustriais, pp. 93-103.

Um tema central da crítica social e ecológica do sistema produtivo capitalista atual é o da sua carência de "sustentabilidade", a partir da refutação de um dogma central da economia política liberal clássica e neoclássica que é o da noção fisiocrática da natureza como um "dom gratuito".

Estamos diante do anúncio de uma catástrofe global: aquecimento global, superpopulação em megacidades de miséria, colapso dos recursos naturais não-renováveis. No ano de 2007, pela primeira vez na história humana, o número de habitantes em cidades superou os do campo.

O autor da chamada "teoria de gaia", James Lovelock, seguindo a concepção do cientista russo Vernadsky, de 1926, de que o mundo é uma "biosfera" (ele foi o primeiro a afirmar que a atmosfera foi produzida pela vida que é uma "força geológica"), vem apontando para os significados da perturbação desse equilíbrio instável.

Não só o efeito estufa, causado pelas emissões crescentes de derivados de carbono, e o esgotamento de recursos não-renováveis como água potável, florestas ou oceanos ameaçam a civilização humana e a vida em geral. Também o ciclo natural do nitrogênio vem sendo alterado de forma acelerada nos últimos dois séculos da revolução agrícola-industrial, mas o mais grave é que essa alteração cresce exponencialmente quanto mais se aproxima do momento contemporâneo.

A ruína do "metabolismo" entre o homem e a natureza, como se referia Marx aos resultados da produção capitalista industrial e agrícola em larga escala, vem se mostrando muito mais apavorante do que poderia se supor no século XIX. Naquele momento, a preocupação central era quanto ao esgotamento da fertilidade natural do solo. As descobertas do papel do nitrogênio, do fósforo e do potássio como nutrientes do solo por Justus Von Liebig, desde 1840, vão se somar a uma constatação do esgotamento da fertilidade agrícola na Grã-Bretanha em plena revolução industrial, resultado direto do amontoamento de seres humanos em cidades insalubres e despovoamento dos campos, levando os refugos a não mais adubarem as 
terras, mas a poluírem os rios. Isso levou a uma importação de insumos, ossos em primeiro lugar (pelos fosfatos) (de 14 mil libras em 1823 para 254 mil em 1837); em seguida de guano, dejetos de aves trazidos do Peru (10 barco em 1835, 1700 t em 1841, 222 mil em 1847), e, finalmente, de nitratos tirados do deserto chileno-peruano-boliviano (o que levou, inclusive, a guerra do Pacífico, em 1879) ${ }^{3}$.

Os significados dos adubos humanos e animais para a agricultura foram tão grandes que James Lovelock chegou a propor a teoria de que o descarte de compostos de amônia na forma de urina foi uma condição simbiótica com a necessidade de nitrogênio (presente na uréia) da vegetação numa co-evolução (semelhante a que se deu entre os humanos e as gramíneas) ${ }^{4}$.

A separação entre cidade e campo no interior de cada país foi equivalente a uma separação global entre países centrais, importadores de insumos e matéria-primas, e países periféricos exportadores de commodities.

Porque sempre falamos das revoluções industriais, muitas vezes esquecendo-nos que também ocorreram, concomitantemente, revoluções agrícolas. Na verdade, são partes de um mesmo processo indissociável de revoluções agroindustriais.

A primeira, no início do capitalismo, correspondeu aos cercamentos (enclosures) e expulsões dos camponeses das terras, à mercantilização das terras, até mesmo as comunitárias alodiais (livres de ônus e obrigações) e, a partir de então, alienáveis. As modificações técnicas na adubação, drenagem, rotação de culturas se somaram à circulação global de novos produtos, dois dos quais passaram a ser indispensáveis e permitiram à Europa superar a retração do século XVII: o milho e a batata.

A segunda revolução agrícola se sucede, no século XIX, à revolução industrial e representa, sobretudo, a mutação nas condições de fertilidade do

\footnotetext{
3 John Bellamy Foster, A Ecologia de Marx. Materialismo e natureza, Rio de Janeiro, Civilização Brasileira, 2005.

4 "Talvez façamos xixi por razões altruístas. Se nós e outros animais não eliminássemos urina, parte da vida vegetal da Terra morreria por falta de nitrogênio", James Lovelock, A vingança de Gaia, RJ, Intrínseca, 2006, p.29.
} 
Estudos sobre alimentação: entre saberes da vida cotidiana e impasses agroindustriais, pp. 93-103.

solo nas regiões industrialmente mais avançadas e sua dependência de importação de fertilizantes.

A terceira, no século $X X$, trouxe a tração mecânica (tratores), a criação em massa de animais confinados, o uso de pesticidas e fertilizantes sintéticos, alterações genéticas de plantas e animais. Os resultados foram não só recordes de produção como barateamento de custos, mas isso não impediu que a fome se mantivesse como um problema global central. Na verdade, o aumento da produtividade agrícola a qualquer preço se tornou agro-poluidora e causadora direta de desigualdades sociais.

Os efeitos da chamada terceira revolução tecnológica ou tecno-industrial do segundo pós-guerra no campo da alimentação, especialmente no que diz respeito às transformações na vida cotidiana e na cultura, são temas centrais para pesquisas que buscam, mais do que as permanências, identificar as mudanças.

A superprodução de grãos e o barateamento dos preços constituem um elemento do "poder alimentar" de alguns oligopólios globais, mas destrói a natureza, destrói as agriculturas periféricas e comunitárias e arruína até mesmo o setor dos fazendeiros do "cinturão do milho" (corn belt) norteamericano, que produzem muitas vezes a um custo de produção que é o dobro do preço do milho, recebendo a parte do prejuízo como subsídio governamental. Em outro momento, a oscilação altista dos preços de alimentos traz devastação social em regiões dependentes de importações como vem ocorrendo nos últimos anos.

Ameaça à biodiversidade pelo uso de transgênicos; doenças da criação de animais em confinamento como a gripe aviária ou de dietas indevidas como a vaca-louca; modelo alimentar humano baseado em carboidratos, gorduras animais e açúcar causando obesidade e outros problemas; expansão de fronteiras agrícolas da soja destruindo a Amazônia. Tais são alguns dos sintomas que refletem o mal-estar em torno da alimentação, cujas causas e 
conseqüências são ecológicas, econômicas e culturais. Infelizmente, ainda não são suficientemente políticas para determinar uma agenda pública alternativa.

A "falha metabólica", no metabolismo entre a humanidade e a natureza agrava-se, a alienação da terra e da natureza torna-se, mais do que produtora de miséria humana, o caminho para a catástrofe sócio-ambiental.

O "prometeísmo tecnológico" vem ameaçando, literalmente pelo fogo, a sobrevivência das florestas na terra ${ }^{5}$. Vivemos hoje uma época pletórica, de pleonexia ou excesso de plenitude, em que a superprodução de alimentos e de outras mercadorias é acompanhada da superprodução de liquidez financeira, de multiplicação de capitais e de estoques que transbordam do excesso de uma civilização perdulária que desafia a sustentabilidade com o uso desmesurado de seus recursos humanos e naturais.

Atualmente se produzem cerca de dois bilhões de toneladas de grãos (milho mais de 700 milhões de toneladas e trigo e arroz cerca de 600), mais um bilhão de toneladas de cana-de-açúcar, 300 milhões de toneladas de oleaginosas, especialmente soja.

Para cada ser humano, entre 300 e 500 quilos de alimentos por ano bastam, o limite em volume sendo quase totalmente inelástico. O que ocorreu no segundo pós-guerra foi a adoção de uma dieta predominantemente carnívora nos países centrais que cada vez mais vem dedicando a agricultura à produção de forragem animal. Para isso, adotou-se um modelo de agronegócios baseado em produção em escala, monocultura extensiva, mecanização e alto uso de insumos tecnológicos, como fertilizantes e pesticidas. Chamado de "revolução verde", esse modelo deslocou a nossa dependência de energia solar para uma dependência de combustíveis fósseis na agricultura, ou seja, cada vez mais comemos petróleo.

Esse modelo de uso de combustíveis fósseis (petróleo, gás natural), de agricultura de um só produto em vastas áreas varridas por agrotóxicos e fertilizantes sintéticos expandiu uma superprodução que não serviu para acabar com a fome e a subnutrição mundial mas para aumentar o food power

\footnotetext{
${ }^{5}$ John Perlin, História das florestas, Rio de Janeiro, Imago, 1992.
} 
dos grandes produtores (sobretudo os EUA) e para criar uma cultura do excesso, do dispêndio perdulário e do hiperconsumo. A carne de animais alimentados por rações e criados em condições de confinamento absorve metade dos antibióticos produzidos no mercado estadunidense e é consumida numa hipertrofia tão grande que criou a maior epidemia de obesidade da história humana.

A maior autoridade de saúde pública da União Européia, Markos Kuprianou, declarou em 31/07/2007 que a maior ameaça à saúde pública européia é a obesidade que já atinge $27 \%$ dos homens e $38 \%$ das mulheres (três vezes mais do que nos anos 80 !) e absorve $7 \%$ do orçamento de saúde.

Estaríamos então, na expressão de Pollan, assumindo um "pacto fáustico" ao adotar em massa uso de fertilizantes e pesticidas a partir do segundo pós-guerra, ambos aliás derivados de readaptações da indústria militar que não necessitava mais de um suprimento tão grande de munições e venenos químicos.

As conseqüências desse modelo são o despovoamento agrário, a explosão de megacidades, a destruição da biodiversidade, o efeito estufa e a eutrofia (excesso de algas nas águas devido ao despejo de fertilizantes, que leva à morte da vida aquática).

Por tudo isso, a história da alimentação contemporânea é também a história da indústria e do crescimento populacional, especialmente urbano, do fim do campesinato e das agriculturas tradicionais e da adoção de padrões dietários baseados em excesso de carne, gorduras animais e açúcares.

Os estudos historiográficos da alimentação deveriam ter sempre presente este pano de fundo, pois nesse campo a tentação é grande para nos debruçarmos sobre os aspectos sócio-culturais, digamos, mais saborosos, do que lembrar a realidade indigesta da crise civilizacional no século XXI.

O sabor, o gosto, o aspecto estético, sensual, afetivo, simbólico, a importância na ritualização da sociabilidade, são dimensões intensamente 
significativas da alimentação que, enraizadas nas camadas mais profundas da vida cotidiana, vem sendo também objetos de um estudo na historiografia da alimentação.

De certa forma, a riqueza da culinária mundial, suas fusões e a valorização de uma "cultura culinária" como forma de expressão artística, refletem, diante de uma crise global da alimentação de massas, a busca de caminhos alternativos que passam, além das saídas macroestruturais, por atitudes individuais e éticas, daí uma retomada de debates sobre vegetarianismo, talvez nunca tão difundido no Ocidente como hoje em dia, formas de agricultura "orgânica" e dos respectivos mercados de produtos "alternativos" que ganham espaço em todos os supermercados. Da mesma forma, uma certa moda de falar de comida misturando culinária, saúde e filosofia parece invadir o espaço midiático e inspirar uma retomada, mesmo que inconsciente e vulgarizada, dos padrões éticos da filosofia grega da "dietética", da temperança e do banquete.

A gastronomia, que foi no passado uma concepção médica e filosófica de uma dietética como regra de bem viver tornou-se, no século XIX, uma forma de teoria do gosto e de sua expressão como forma de arte. E, portanto, uma forma de distinção social. A burguesia ascendente buscou apropriar-se dos recursos simbólicos da aristocracia estabelecendo o acesso a eles por meio do talento e do dinheiro e não pela nobreza do sangue. As belas-artes e o bem viver ampliaram sua abrangência, democratizaram-se.

Nos dias de hoje, gastronomia se tornou uma espécie de alta-cultura da cozinha, e por isso, diferente da cozinha cotidiana, feminina, caseira, a gastronomia é dos chefs homens, um domínio tão machista que chegou a haver tentativas na França de se impedir as mulheres de usarem aquele chapéu típico de chef.

Os estudos sobre alimentação são desafiados a buscar um enfoque que tente dar conta da amplitude micro e macro das questões históricas da alimentação exatamente na medida em que estas esferas não são autônomas, mas, ao contrário, se relacionam, não só no sentido de uma determinação do 
Estudos sobre alimentação: entre saberes da vida cotidiana e impasses agroindustriais, pp. 93-103.

macro que incide sobre o micro, pois este se desenrola numa espessura mais densa da temporalidade, o cotidiano, mas também na emergência de uma ação das partes sobre o todo.

\section{Bibliografia:}

DE CERTEAU, Michel; GIARD, Luce; e MAYOL, Pierre, A invenção do cotidiano, 2. Morar, Cozinhar, 8a Ed., Editora Vozes, 2008.

FOSTER, John Bellamy, A Ecologia de Marx. Materialismo e natureza, Rio de Janeiro, Civilização Brasileira, 2005.

LOVELOCK, James, A vingança de Gaia, RJ, Intrínseca, 2006.

PERLIN, John, História das florestas, Rio de Janeiro, Imago, 1992.

POLLAN, Michael, o Dilema do Onívoro, Rio de Janeiro, Intrínseca, 2007. 